\title{
A 140 MW solar thermal plant with storage in Ma'an, Jordan
}

\author{
Wael Al-Kouz ${ }^{1, *}$, Ahmad Almuhtady ${ }^{2}$, Jamal Nayfeh $^{1}$, Nidal Abu-Libdeh $^{3}$, Alberto Boretti ${ }^{1, *}$ \\ ${ }^{1}$ Mechanical Engineering Department, College of Engineering, Prince Mohammad Bin Fahd University, Saudi Arabia \\ ${ }^{2}$ Mechanical and Maintenance Eng. Dept., School of Applied Technical Sciences. German Jordanian University, Jordan \\ ${ }^{3}$ Curriculum Department, Prince Mohammad Bin Fahd University, Saudi Arabia
}

\begin{abstract}
In this paper, a $140 \mathrm{MW}$ solar thermal plant with thermal energy storage is proposed for Ma'an, Jordan. The plant characteristics are derived from the design of the Solana solar thermal plant with thermal energy storage in Gila Bend, AZ, US. One half of the solar field is considered, and only 1 of the 2 turbines. The total capacity is reduced from $280 \mathrm{MW}$ gross, $250 \mathrm{MW}$ net to $140 \mathrm{MW}$ gross, $125 \mathrm{MW}$ net. Energy storage is designed for 6 hours, the same as Solana. The performances of this plant similar to Solana are analyzed by using the System Analyser Modeller (SAM) software. Simulations show that Ma'an is a superior location for implementing this design, as the capacity factors are generally better in this location over the year.
\end{abstract}

\section{Introduction}

Jordan as a country is very well known for its solar resources. Jordan receives annual global radiation of about $2,000 \mathrm{kWh} / \mathrm{m}^{2}$ [1-2]. Therefore, many works have been done investigating applications that involve renewable energy such as desalination, power generation, and Heating, Ventilation, and Air Conditioning (HVAC) [3-9]. Moreover, many researchers studied the effects of climatic conditions such as temperature, wind speed, and dust on the performance of renewable energy systems [10-12]

The potential of a Concentrated Solar Power (CSP) in Jordan becomes clear as soon as the weather conditions are compared to those of the most successful CSP power plants (for example Solana, in Gila Bend, AZ, US). In this research, we use a validated model for Solana in Gila Bend, AZ, US to compute the performances that a similar model may have in Ma'an, Jordan. Simulations were carried out using the System Advisor Model (SAM) simulations. SAM [13]. CSP modeling details in SAM can be found in [14-19].

Concentrated solar power (CSP) can be exploited through systems employing Solar Tower (ST) or parabolic trough (PT). Despite theoretically it is the opposite, in real-world, the capacity factors, which are the ratio of the average power during a period to the nominal power, are better in PT systems in comparison to ST ones [20-24]. Coupling CSP with molten salt thermal energy storage (TES) enhances its energy dispatchablity. The CSP power cycle operates between the temperature at the exit of the solar field and the temperature of the condenser, air-cooled, or evaporative cooling.

\section{Materials and methods}

CSP PT models can be easily developed in SAM [10 13]. First, we target the validation of the physical parabolic trough model in SAM Version 2018.11.11, updated to Revision 4, SSC 209, by comparing monthly average experimental data with simulations for the average year [25]. Then, we focus on the Solana plant, which is CSP PT with 6 hours of molten salt TES. This plant is the one delivering the best annual average capacity factors, presently about $36.4 \%$, while at the same time permitting electricity production during the summer after sunset up to about midnight. The simulations are in good agreement with the measured data [25], despite a comparison of only monthly values of capacity factors experimental - computational is not enough for proper validation. The main components of a parabolic trough system are the solar field, power block, and thermal energy storage. More comprehensive validation of the SAM code for the simulation of CSP plants, plus the basics of the CSP modeling, is provided in [25], with a comparison of experiments and simulations for 4 major CSP plants, both ST and PT with and without TES.

\section{Results}

After the model was validated, the Solana model was modified to simulate the operation in Ma'an, Jordan. Figure 1 shows the location of Ma'an on the map of country Jordan, together with the resource. Summarized below in table 1 are the environmental conditions for Ma'an, along with Gila Bend in AZ, US that is the location where the physical plant of Solana is located.

*orresponding author: walkouz@pmu.edu.sa ; a.a.boretti@gmail.com 
Table 1. Weather conditions for the two different locations considered in the study.

\begin{tabular}{|c|c|c|}
\hline parameter & Gila Bend & Ma'an \\
\hline $\begin{array}{l}\text { direct normal irradiation } \\
\text { (DNI) }\end{array}$ & $2779 \mathrm{kWh} / \mathrm{m}^{2}$ & $2798 \mathrm{kWh} / \mathrm{m}^{2}$ \\
\hline $\begin{array}{l}\text { average global horizontal } \\
\text { irradiation GHI }\end{array}$ & $2154 \mathrm{kWh} / \mathrm{m}^{2}$ & $2327 \mathrm{kWh} / \mathrm{m}^{2}$ \\
\hline $\begin{array}{l}\text { average diffuse horizontal } \\
\text { irradiation DIF }\end{array}$ & $473 \mathrm{kWh} / \mathrm{m}^{2}$ & $524 \mathrm{kWh} / \mathrm{m}^{2}$ \\
\hline $\begin{array}{l}\text { average global tilted } \\
\text { irradiation at an optimum } \\
\text { angle (GTI Opta) }\end{array}$ & $2490 \mathrm{kWh} / \mathrm{m}^{2}$ & $2578 \mathrm{kWh} / \mathrm{m}^{2}$ \\
\hline average air temperature & $24.9^{\circ} \mathrm{C}$ & $18^{\circ} \mathrm{C}$ \\
\hline terrain elevation & $222 \mathrm{~m}$ & $1108 \mathrm{~m}$ \\
\hline
\end{tabular}

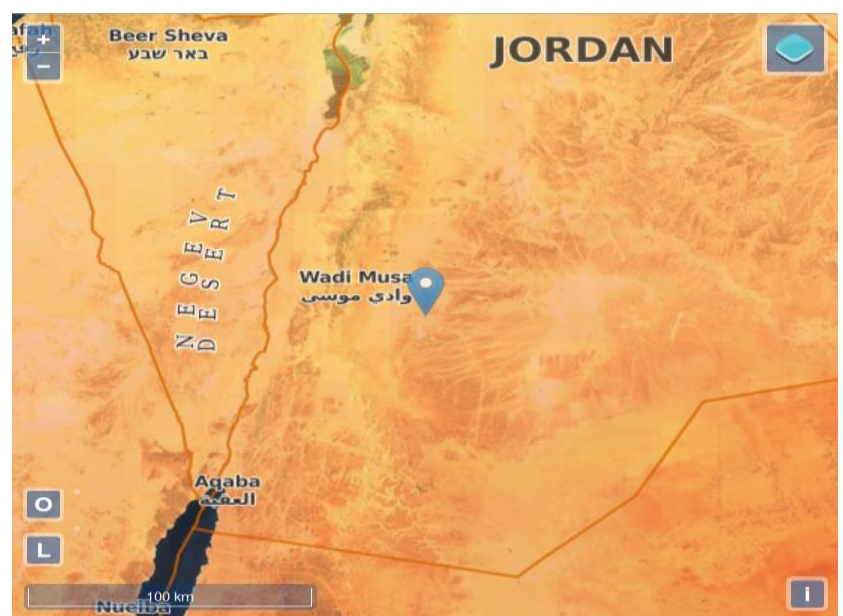

Fig. 1. location of the proposed power plant. Image reproduced modified from

https://re.jrc.ec.europa.eu/pvg tools/en/tools.html\#TMY

In this research, the generic model for parabolic trough with thermal energy storage with molten salts in SAM is utilized. Results of simulations are shown in Figures 2,3,4,5,6, for a plant similar to Solana, with however one half the solar field and only 1 of 2 turbines. Figure 2 is the total thermal energy absorbed by the solar field, the total thermal energy to the power block, and the total energy delivered to the grid, every month. The absorbed energy peaks in July, and it has a minimum in January.

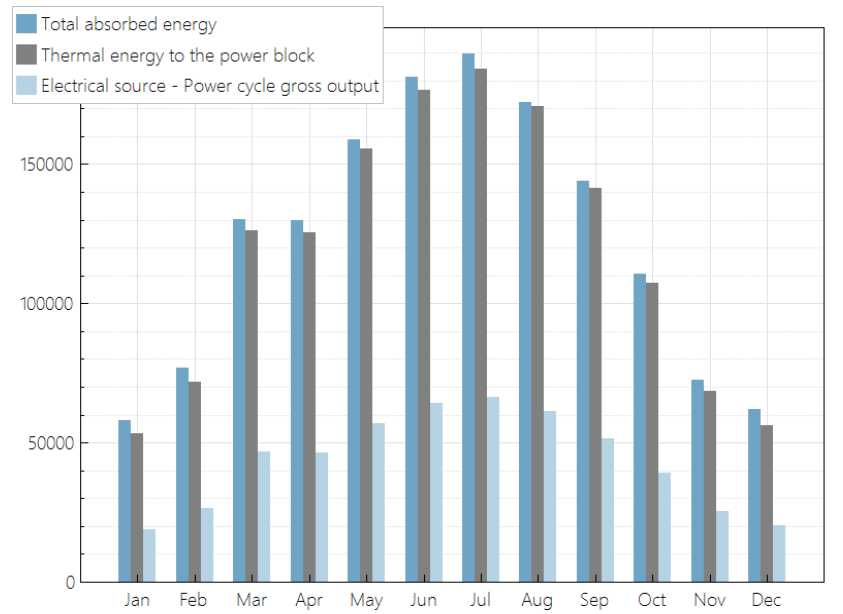

Fig. 2. Computed total thermal energy absorbed by the solar field, total thermal energy delivered to the power block, and total energy delivered to the grid, every month.
Figure 3 is the power from the solar field, the power to the thermal energy storage, and the power to the power block during the typical day of every month. The power from the solar field is enough to run the turbine and charge the storage during the day from February to October. This permits to extend electricity production after the sunset during 9 months of 12 , albeit at a different extent. April to September power generation occurs up to mid-night.
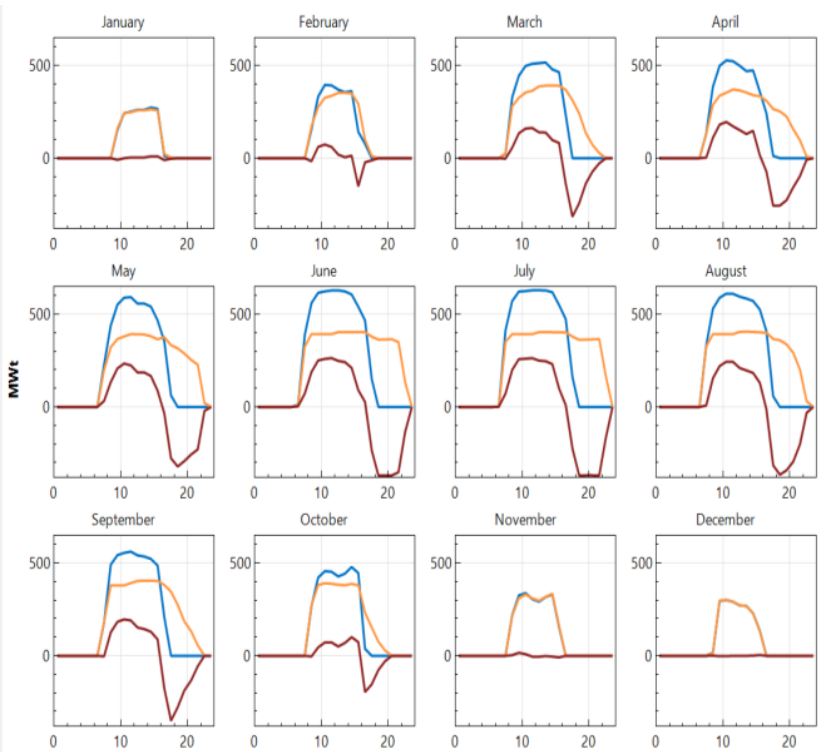

Fig. 3. Computed power from the solar field, the power to the thermal energy storage, and the power to the power block during the typical day of every month.

Figure 4 is the gross and net power of the turbine. April to September the power generation extends to almost mid-night. The difference between gross and net power output at the turbine is about $90 \%$.
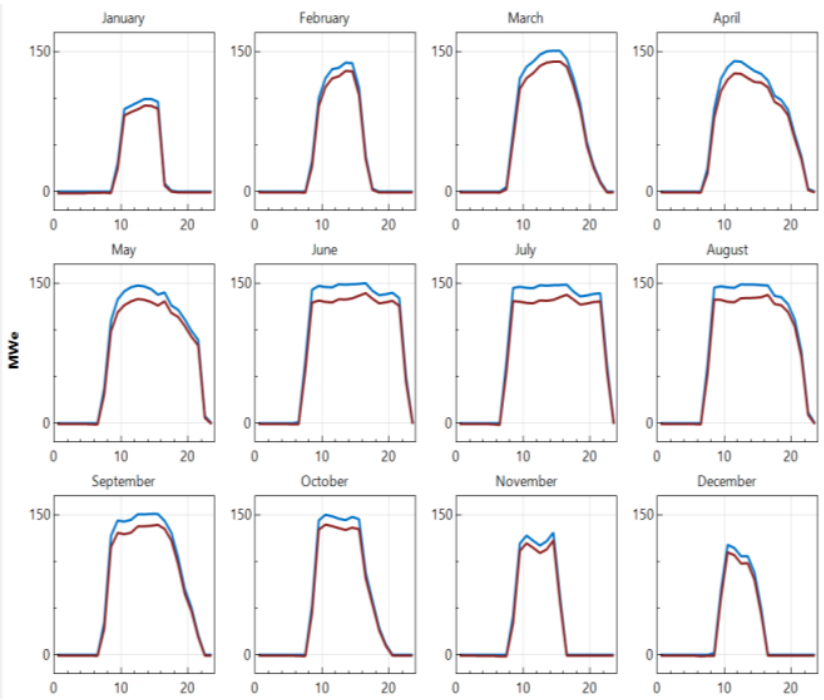

Fig. 4. Computed gross and net power from the turbine.

Figure 5 presents the computed gross electricity generation from the turbine (maximum is $140 \mathrm{MW}$ gross, $125 \mathrm{MW}$ net) as a function of the hour in the day and the day in a year. May to August a good generation is possible from $8 \mathrm{AM}$ to $10 \mathrm{PM}$. 


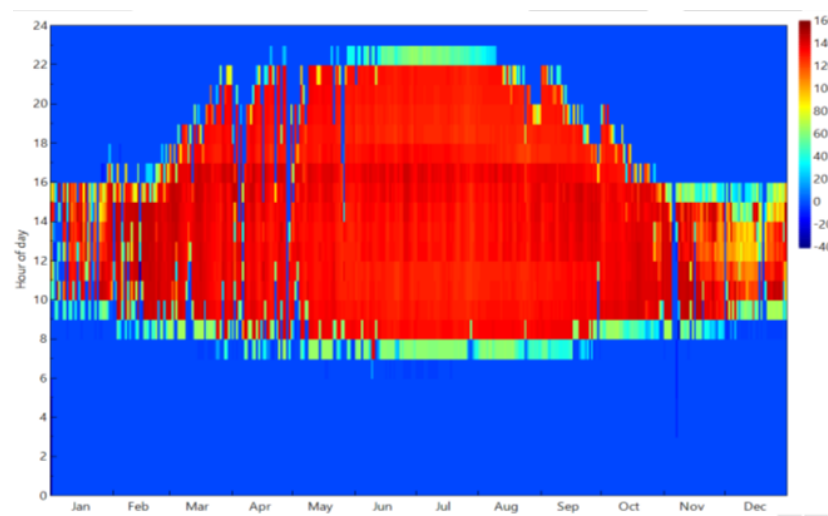

Fig. 5.Computational gross electricity generation from the turbine (maximum is $140 \mathrm{MW}$ gross, $125 \mathrm{MW}$ net) as a function of the hour in the day and the day in a year.

Figure 6 finally presents the computed capacity factors over the year. The average capacity factor is $37 \%$. IN June and July the capacity factors are above $56 \%$.

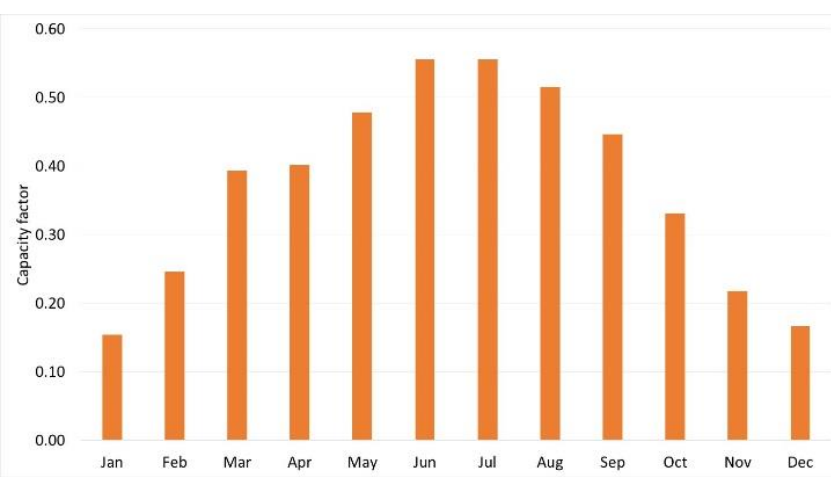

Fig. 6. Computed capacity factors over the year.

The power from the solar field is enough to run the turbine and charge the storage during the day from February to October. This permits to extend electricity production after the sunset during 9 months of 12, albeit at a different extent. April to September power generation occurs up to mid-night. In Ma'an the solar energy collected from the solar field during winter is insufficient to run the facility at peak power as well as to charge the thermal energy storage. Then, in peak summer, the solar energy collected

from the solar field is enough to run the facility at peak power and to store energy in the storage for the production of electricity up to almost mid-night in July. Then, going back to the winter, the solar energy collected during the day reduces, and these limits peak energy production during the day as well as the opportunity to store energy for after sunset operation.

The increased size of the solar field may increase the capacity factor. By increasing the solar field aperture from $1,120,000 \mathrm{~m}^{2}$ to $1,232,000 \mathrm{~m}^{2}$ the annual average capacity factor increases up to $39 \%$. By also increasing the full load hours of TES to 10 hours, the annual average capacity factor increases up to $42 \%$. Figures $7,8,9,10$ and 11 present the results similar to Figures $2,3,4,5,6$ in this later configuration with increased solar field surface and increased TES.

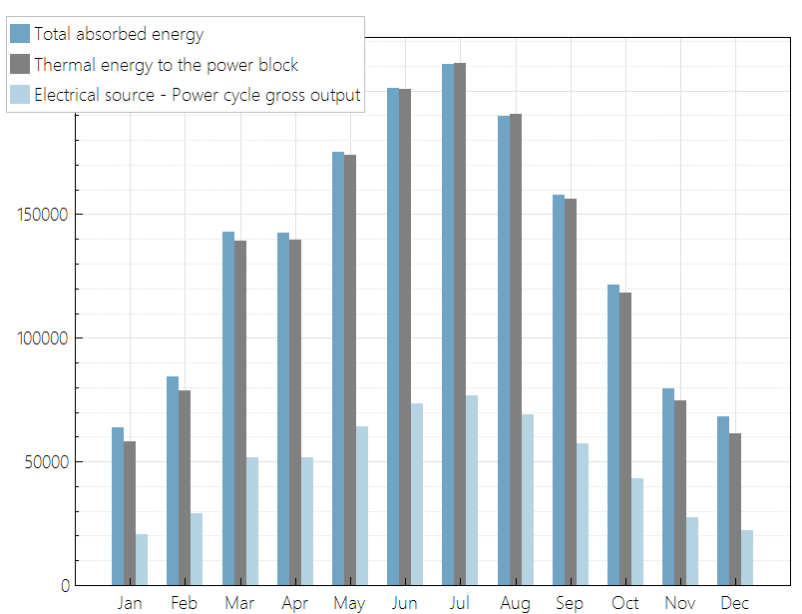

Fig. 7. Computed total thermal energy absorbed by the solar field, total thermal energy delivered to the power block, and total energy delivered to the grid, every month. $10 \%$ increased solar field surface and TES increased to $10 \mathrm{~h}$.
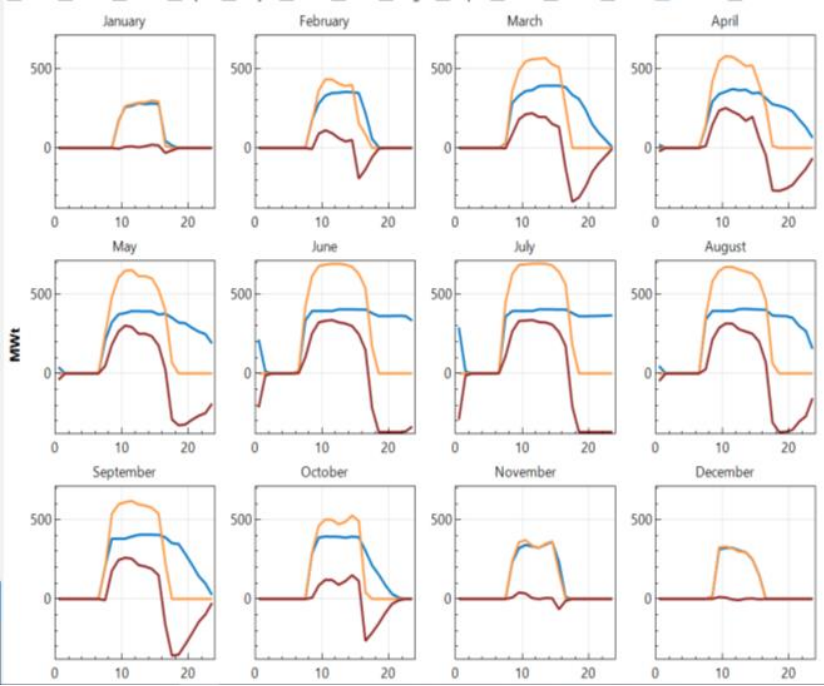

Fig. 8. Computed power from the solar field, the power to the thermal energy storage, and the power to the power block during the typical day of every month. $10 \%$ increased solar field surface and TES increased to $10 \mathrm{~h}$.
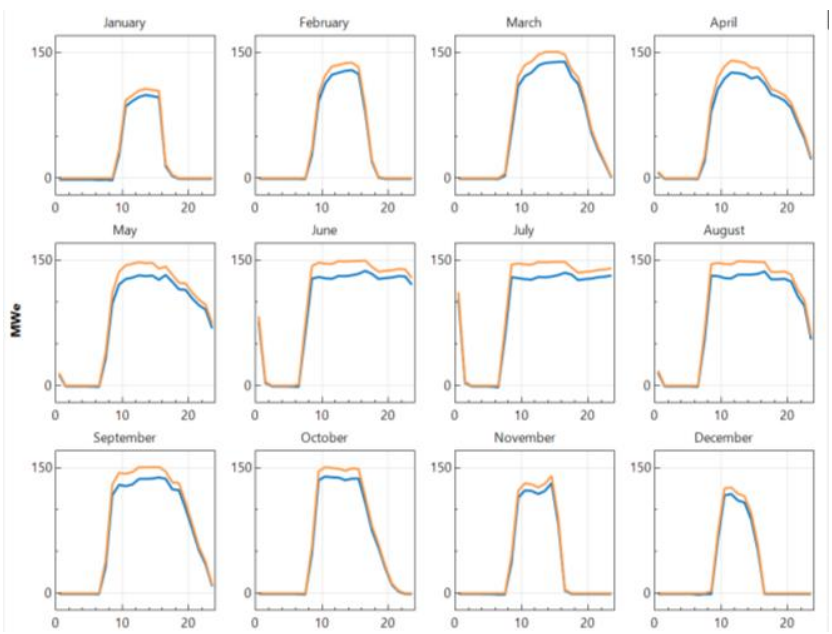

Fig. 9. Computed gross and net power from the turbine. 10\% increased solar field surface and TES increased to $10 \mathrm{~h}$. 


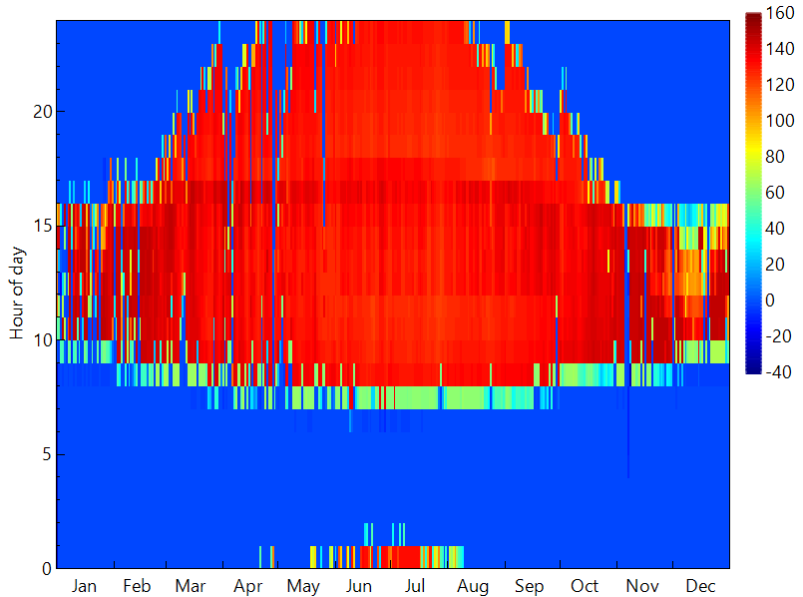

Fig. 10.Computational gross electricity generation from the turbine (maximum is $140 \mathrm{MW}$ gross, $125 \mathrm{MW}$ net) as a function of the hour in the day and the day in a year. 10\% increased solar field surface and TES increased to $10 \mathrm{~h}$.

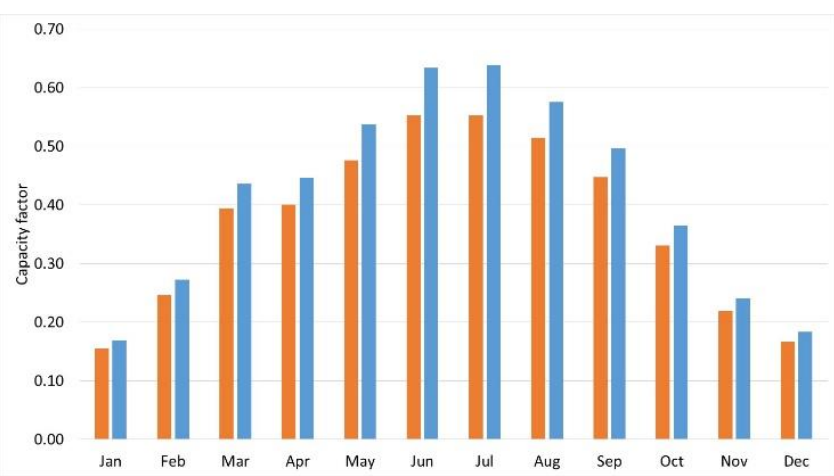

Fig.11. Computed capacity factors over the year. $10 \%$ increased solar field surface and TES increased to $10 \mathrm{~h}$.

With the increased solar field and the increased TES, the operation dramatically improves, with much better capacity factors on average, and prolonged operation during the night.

Operation in Ma'an is better than Gila Bend because of the larger solar irradiance, the reduced humidity, and the lower minimum temperature in Ma'an. The electricity production is close to the one in Gila Bend, which is considered one of the best places on earth for solar power, with the baseline plant.

\section{Discussion and Conclusions}

Data from built and run plants reveals that, opposite to theoretical expectations, CSP PT plants have larger capacity factors than CSP ST plants. From these experiences, it seems logical to avoid the construction of a CSP ST in Jordan. As these CSP ST projects did not achieve the designed capacity factors in the US, there is no reason why they could work better in Ma'an. From the US experience, selecting a CSP PT design has a better prospect for better performances and reduced costs. The dispatchability in electricity generation points to an almost certain future direction of TES. The choice of the CSP technology for Jordan is thus the CSP PT with TES of Solana, with an increase in the energy storage to 10 hours, and an increased in the solar field of $10 \%$. Increasing the capacity of the TES improves both the monthly electricity production, as well as the dispatchability. The TES increment is dependent to the integration of solar power with other electricity sources and the pricing of the electricity. The choice of Solana is inspired by the fact of being the only plant having currently a proven advantage on standard PV systems, delivering better annual average capacity factor, which a likely smaller standard deviation thanks to the TES. A pilot plant study must be performed first, before moving to a full-scale realization, as the models still lack validation. Improvement of the Technology Readiness Level of CSP PT with TES is also a necessary condition before progressing in large expenditures for plants not yet proven to work as expected.

\section{References}

1. Meteotest (2003) METEONORM Global Meteorological Database for Engineers, Planners and Education.

2. Mamlook, R., Akash, B. A., \& Nijmeh, S. (2001). Fuzzy sets programming to perform evaluation of solar systems in Jordan. Energy Conversion and Management, 42(14), 1717-1726.

3. Akash, B. A., Mamlook, R., \& Mohsen, M. S. (1999). Multi-criteria selection of electric power plants using analytical hierarchy process. Electric Power Systems Research, 52(1), 29-35.

4. Odeh, S., Nijmeh, S., \& Akash, B. (2004). Performance evaluation of solar-assisted doubletube evaporator heat pump system. International communications in heat and mass transfer, 31(2), 191-201.

5. Alata, M., Al-Nimr, M. A., \& Qaroush, Y. (2005). Developing a multipurpose sun tracking system using fuzzy control. Energy Conversion and Management, 46(7-8), 1229-1245.

6. Jaber, J. O., Elkarmi, F., Alasis, E., \& Kostas, A. (2015). Employment of renewable energy in Jordan: Current status, SWOT and problem analysis. Renewable and Sustainable Energy Reviews, 49, 490-499.

7. Akash, O. B., Abdo, A. M. A., Mohsen, M. S., \& Akash, B. A. (2016). A Note on Solar Energy Research in Jordan. International Journal of Applied Engineering Research, 11(10), 7100-7105.

8. Moh'd A, A. N., Bukhari, M., \& Mansour, M. (2017). A combined CPV/T and ORC solar power generation system integrated with geothermal cooling and electrolyser/fuel cell storage unit. Energy, 133, 513-524.

9. Almuhtady, A., Alshwawra, A., Alfaouri, M., AlKouz, W., \& Al-Hinti, I. (2019). Investigation of the trends of electricity demands in Jordan and its susceptibility to the ambient air temperature towards sustainable electricity generation. Energy, Sustainability and Society, 9(1), 1-18.

10. Nader, N., W. Al-Kouz, S. Al-Dahidi. (2019). Assessment of Existing Photovoltaic System with 
Cooling and Cleaning System: Case Study at AlKhobar City. Processes, 8(1), 9. doi:10.3390/pr8010009 16.

11. Al-Kouz, W., S. Al-Dahidi, B. Hammad, M. AlAbed. (2019). Modeling and Analysis Framework for Investigating the Impact of Dust and Temperature on PV Systems' Performance and Optimum Cleaning Frequency. Applied Sciences, 9(7), 1397. doi: 10.3390/app9071397

12. Al-Bashir, A., M. Al-Dweri, A. Al-Ghandoor, B. Hammad, W. Al-Kouz. (2020). Analysis of Effects of Solar Irradiance, Cell Temperature and Wind Speed On Photovoltaic Systems Performance. International Journal of Energy Economics and Policy, 10(1), 353-359. doi:10.32479/ijeep.859

13. National Renewable Energy Laboratory, (2019), System Advisor Model (SAM) - NREL, sam.nrel.gov

14. Wagner, M., (2014), Modeling Parabolic Trough Systems, Jun 2014. sam.nrel.gov/images/webinar_files/sam-webinars2014-parabolic-trough-systems.pdf

15. Blair et al., (2018), System Advisor Model (SAM) General Description (Version 2017.9.5), NREL/TP6A20-70414. www.nrel.gov/docs/fy18osti/70414.pdf

16. Lopes, F.; Ricardo Conceição, R.; Silva, H.; Fasquelle, T.; Salgado, R.; Canhoto, P.; CollaresPereira, M., (2019), Short-Term Forecasts of DNI from an Integrated Forecasting System (ECMWF) for Optimized Operational Strategies of a Central Receiver System. Energies, Vol. 12 No. 7 p 1368.

17. Kesseli, D.; Wagner, M.; Guédez, R.; Turchi, C., (2018). CSP-Plant Modeling Guidelines and Compliance of the System Advisor Model (SAM). DRAFT SolarPACES Conference Paper. sam.nrel.gov/sites/default/files/content/documents/ pdf/SolarPACES_2018_GuiSmo_DRAFT_v5.pdf

18. Wagner, M. J.; Gilman, P., (2011). Technical Manual for the SAM Physical Trough Model. 124 pp.; NREL Report No.TP-5500-51825. www.nrel.gov/docs/fy11osti/51825.pdf
19. Turchi, C.; Neises, T., (2015). Parabolic Trough Solar-Thermal Output Model Decoupled from SAM Power Block Assumptions. Milestone report prepared for the U.S. Department of Energy. sam.nrel.gov/sites/default/files/content/usersupport/DOE\%20Milestone $\% 20$ Report $\% 20$ $\% 20$ Stand alone $\% 20$ Parabolic $\% 20$ Trough $\% 20$ code $\% 202015$ 03-30.pdf

20. Boretti, A., (2018), Concentrated Solar Power Plants Capacity Factors: A Review, Nonlinear Approaches, in Engineering Applications Energy: Vibrations, and Modern Applications, Liming Dai, Eds., Reza N. Jazar, Springer, New York.dx.doi.org/10.1007/978-3-319-69480-1_2

21. Boretti, A., S. Castelletto, and S. Al-Zübaidy, (2018), Concentrating solar power tower technology: present status and outlook, Nonlinear Engineering - Modeling and Application (NLENG). Volume 8, Issue 1. Published Online: 2018-05-22. Ahead of print. doi.org/10.1515/nleng-2017-0171

22. Boretti, A., (2018), Cost and Production of Solar Thermal and Solar Photovoltaics Power Plants in the United States, Renewable Energy Focus. Volume 26, September 2018, Pages 93-99. doi.org/10.1016/j.ref.2018.07.002

23. Boretti, A. and Al-Zubaidy, S., (2019), A case study on combined cycle power plant integrated with solar energy in Trinidad and Tobago, Sustainable Energy Technologies and Assessments, vol. 32, pp. 100-110. doi.org/10.1016/j.seta.2019.02.006

24. Boretti, A., (2019), Realistic expectation of electricity production from current design concentrated solar power solar tower with thermal energy storage, Energy Storage, Volume1, Issue3, June 2019, e57. dx.doi.org/10.1002/est2.57.

25. Boretti, A., J. Nayfeh and W. Al-Kouz, (2020), Validation of SA modeling of concentrated solar power plants, Energies, 13 (8), doi:10.3390/en13081949 